\title{
An innovative system for the acquisition and analysis of energy and utilities consumption data dedicated to smart energy cities
}

\author{
Piotr Ziembicki, ${ }^{1, *}$ \\ ${ }^{1}$ University of Zielona Góra, Faculty of Civil Engineering, Architecture and Environmental \\ Engineering, Prof. Z. Szafrana 15 str., 65-516 Zielona Góra, Poland
}

\begin{abstract}
Buildings in Poland are very energy-consuming, especially during their exploitation. As a result, there is a need for establishing new systems and technologies which could increase energy efficiency in this sector. One of the most important reasons is the lack of technologies and systems dedicated to managing energy and utilities for buildings or building compounds in urban areas. Wide implementation of these kinds of systems, which will operate based on measured on-line data, will ensure a decrease in energy and utilities consumption. At the beginning of the paper, some basic demands of exploitation data acquisition systems are described. The specifics of energy and utilities consumption data are presented. In the main body of the paper, a conception of an innovative system for the acquisition and analysis of energy and utilities consumption data dedicated for buildings is presented, which makes it possible to decrease heat, energy and utilities consumption in urban areas. Some basic systemic assumptions are presented and fundamental technical aspects are described. In addition, the essential assumptions of data analysis algorithms are described in the article.
\end{abstract}

\section{Introduction}

A rise in energy consumption at a global scale is unavoidable [13,15,19,22,25,29]. It is a measure of the success of the economy and the community of a given country. The highest increase of energy consumption concerns the consumption of electric energy and fossil fuels (mainly in transportation). It is also very likely to reverse the current, decreasing trend concerning heat demand in urban agglomerations, due to the more and more popular technologies of using heat for the production of other forms of energy, for example, cooling (most frequently in the form of the so called "chilled water") for the needs of airconditioning systems in buildings serving various purposes [28,32]. This may result in increasing the production of district heat (generated and distributed in the district heating systems).

Also in Poland, the increase in energy consumption constitutes a serious challenge, especially in the context of low energy efficiency for construction and industrial purposes

\footnotetext{
*Corresponding author: p.ziembicki@iiis.uz.zgora.pl
} 
[19]. Analyses of the construction market reveal that nearly twice as much energy is consumed per building surface unit as in the European Union [23]. This indicator applies to both housing construction, office buildings, as well as to public facilities administered by Local Government Institutions. This significantly increases the operating cost of buildings as well as escalates the emission of pollutants into the atmosphere (generated during the production of electricity and heat), which negatively affects the quality of air in urban areas - resulting in, among others, an unfavourable and very harmful phenomenon called SMOG.

\section{Smart Energy Cities}

In the currently available literature, the concept of a Smart Energy City has not been conclusively defined. However, in each definition the authors emphasise that the key element of the concept lies in the use of information and communication technologies in order to increase the interactivity and efficiency of urban infrastructure and its components, as well as in the stimulation of awareness in residents $[5,9,10,16,20,26,34]$. In the context of energy management of urbanised areas, the "Energy" component of the notion is important, which emphasises that municipal energy systems used for the generation and distribution of all forms of energy are analysed in these areas, as well as the furnishing of buildings, which affects their maintenance efficiency.

In a broad sense, municipal power systems include municipal power networks, district heating and cooling networks, heat distribution centres in buildings, as well as district or individual heat sources, including RES, or associated heat and power sources. These systems are extremely complex, often very heavily dispersed, as well as diversified in terms of technical and ownership compatibility. As a result, technical analysis and operational optimisation, in order to reduce energy / utilities consumption (including transmission losses), is a very serious challenge and should be implemented based on exploitation data from measuring devices located in key places of these systems and most of all, at the receiving ends of energy, heat and utilities [3,7,8]. However, it should be emphasised that in addition to the collection and archiving of measurement data and their automatic (intelligent) analysis, modern energy systems functioning under the label Smart Energy City should be able to adapt to recommendations based on conclusions from the implemented analytical algorithms $[1,2,6]$. It can therefore be concluded that the key areas of urban energy systems operating under the Smart Energy City label include [4, 17]:

- intelligent measuring infrastructure (hardware: sensors, data meters, etc.),

- reliable, relevant, efficient and secure ICT systems, intended for the transmission of exploitation data and regulatory signals,

- database software and systems for processing huge amounts of data and making decisions (recommendations for regulatory systems) in real time,

- regulatory automation applications and devices (executive systems) enabling prompt response to signals from analytical systems.

Only such an approach to urban energy systems will facilitate the implementation and integration of small-scale energy technologies in the areas of urban units that may be labelled as energy prosumers (i.e. simultaneous producers and consumers of energy as part of an integrated energy system). Individual customers and/or settlement institutions, such as municipalities, cities or districts, may be such energy prosumers.

\section{Exploitation data collection and analysis system}

The concept of the exploitation data collection and analysis system, presented in this publication, was born in the wake of a research and implementation project under the 
program "Bonus for innovation - support of Lubuskie SME enterprises in the field of research, development and implementation", whose basic assumption is to reinforce cooperation between Lubuskie SMEs and the R \& D sphere and professional advisory institutions, by creating conditions for the transfer of research, modern technologies, knowledge and innovation to these enterprises, leading to an increase in their level of innovation and competitiveness. The research and implementation project is implemented by the Science and Technology Park of the University of Zielona Góra in cooperation with the Institute of Environmental Engineering of the University of Zielona Góra.

The main objective of the research and implementation project is the development and implementation (construction of a pilot installation) of an innovative, distributed system for the registration, archiving and analysis of operational data related to the consumption of all forms of energy (including electricity, heat, cold) and media (hot utility water, cold utility water, gas, special media, etc.) in buildings for various purposes. The system consists of two integrated and cooperating parts:

- technical, which includes devices for recording operational data together with the tele-transmission infrastructure (partly using the existing solutions offered by external manufacturers, and partly based on own solutions),

- database-analytical, which includes a relational database with software designed for its operation, edition and management, as well as integrated analytical software (Expert System) equipped with advanced algorithms for data analysis (Data Mining) supported by expert knowledge.

The purpose of the analysis of operating data obtained from measuring devices is contained in widely understood, multi-criteria optimisation of energy and media consumption, which will lead to the reduction of their consumption by means of such measures as: prompting building administrators with potential initiatives (e.g. location of the largest reception ends, searching for leaks, detection of erroneous measurements, location of fraud attempts), indication and optimisation of thermo-insulation, provision of knowledge for optimal maintenance and many, many more.

The implementation of the exploitation data collection and analysis system was divided into three stages. In the first stage, the necessary preparatory work was carried out, such as: the structure of the relational database, database system mechanisms and analytical software algorithms were defined, proprietary solutions for the registration and transmission of measurement data were developed, and specific, existing solutions were identified along with detailed methodology for their application within the system. At this stage, a system platform (operating system, hardware infrastructure and database engine), as well as the web (network), on which the database and analytical software will be operated, were also selected. The programming language and programming environment were also specified.

In the second stage of the project, which is currently in progress, a complete database and analytical software will be created, and mechanisms for integrating recording devices with this software will be developed. In the third stage, the entire pilot system will be implemented and launched in an indicated cluster of buildings. At this stage, system tests (both hardware and software) will be carried out and any errors occurring during testing will be removed.

\subsection{The hardware}

The technical infrastructure of the exploitation data collection and analysis system within the framework of the research and implementation project may vary in relation to the types and parameters of the monitored measuring devices, to the range of data transmitted (spatial distribution) and to the designated tasks. At the stage of the system concept development, it 
was assumed that the basic requirement regarding the technical equipment of the system would include the introduction of monitoring procedures with regard to all the components of the municipal energy system, i.e.:

- BMS systems, collecting and analysing data on energy consumption in individual buildings,

- heat sources (centralised, clustered or local),

- micro CHP units,

- renewable energy systems,

- heat container or containers.

However, it should be emphasised that despite the stipulation of technical requirements for measuring equipment, during the implementation of the data collection and analysis system in a given building, a heat source or, more broadly, a municipal energy system, it is necessary to make decisions regarding the design and properties of sensors and measuring transducers. The most important elements taken into account are the technological features of the devices and the possibility of their integration with the visualisation of the measured parameters developed and implemented as part of the technical project, the method of data transmission and the functionality of the analytical software. The key features taken into account in the selection of sensors and measuring devices are the following:

- cyclical reading of parameters and their processing into physical units,

- reliability of measurements and durability of power supply,

- automatic control of breeches in technological limitations,

- automatic control of the permissible speed in parameter changes,

- generating alarm and information messages,

- remote diagnostics and the testing of the efficiency of measuring devices.

Within the technical infrastructure of the data collection and analysis system, various parameters are measured, including: temperature, flow (e.g. water, gas), amount of heat and cold, electricity consumption, etc. A detailed specification of measuring elements exceeds the scope of this publication and as such, it will not be stipulated. However, it should be emphasised that in the case of all the monitored parameters, a detailed recognition of both types of devices as well as the location of measurement points were made. A diagram of one of the variants of energy source measurement for a building equipped with a solar collector installation is presented in Fig. 1.

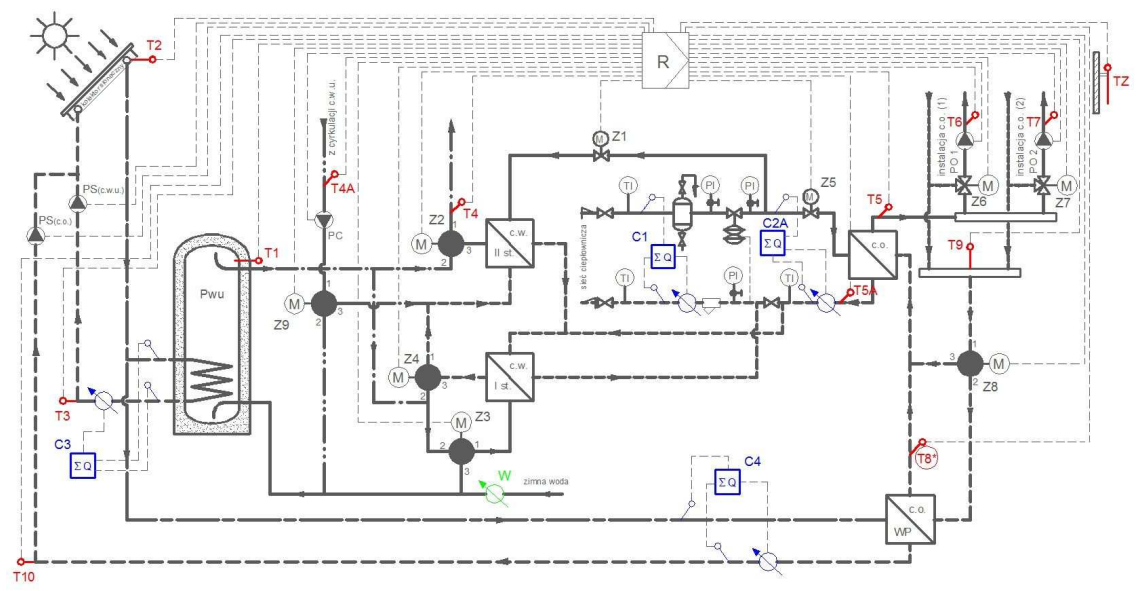

Fig. 1. Diagram of one of the heat source measuring variants $(\mathrm{C}$ - heat meter, $\mathrm{T}$ - temperature measurement). 
ICT infrastructure constitutes an extremely important technical component of the exploitation data collection and analysis system, which is intended for the transmission of measurement data from a measuring device to the "cloud" in which the database and analytical software operates. The potential of the use of particular communication systems, available in built-up areas for its use in the monitoring and telemetry of municipal energy systems, is determined both by technical and financial constraints [27,30]. Digital technologies, which are developing very quickly, are the most suitable, which results in their increased availability and lower costs. At the developmental stage of the system, some assumptions regarding communication between devices were adopted, which should contain the following $[11,12,31]$ :

- connection types: switchable or permanent, owned or leased, wired, remote, mobile telecommunication, etc.

- unified standard of communication connections,

- two-way communication option,

- data transmission security,

- the potential for redundancy of telecommunications connections,

- scalability of solutions.

The communication potential and logical structure constitute a basis for defining network topology, i.e. configuration of connections within the system of telemetric devices. At the same time, just as in the case of measuring devices, a specific implementation of the data collection and analysis system in built-up areas requires analyses of the locally available data transmission potential and only after its completion, a solution recommended during the implementation of the concept in the research and implementation project, may be adopted.

\subsection{The database, software and analytical algorithms}

One of the innovative solutions developed as part of the research and implementation project and used in the exploitation data collection and analysis system is its database and analytical component, which is a cloud-based computing software designed for the simultaneous servicing of collected exploitation data and their detailed analysis in real time. It includes a relational database with system software (engine) as well as analytical software (Expert System) equipped with advanced algorithms for expert-supported data analysis.

Designing a relational database for the requirement of the system involved the creation of an abstract structure for storing physical data which are sent from measuring devices (Fig. 2). In the case of relational databases, they are analogous to a table whose columns are intended for data fields, and rows for information input. In order for the table to be cohesive and functional, its fields must contain elementary (unit) information, as placing all the necessary data in one table is incompatible with the concept of a relational database, data are usually placed in many such structures which group similar data together. In the case of measurement database, separate tables are intended for the construction and technological data of buildings, for energy sources, as well as for the collected exploitation data of particular forms of energy or utilities. The relationships used to determine interaction between records (rows) are the binding element which aggregates data from different tables. 


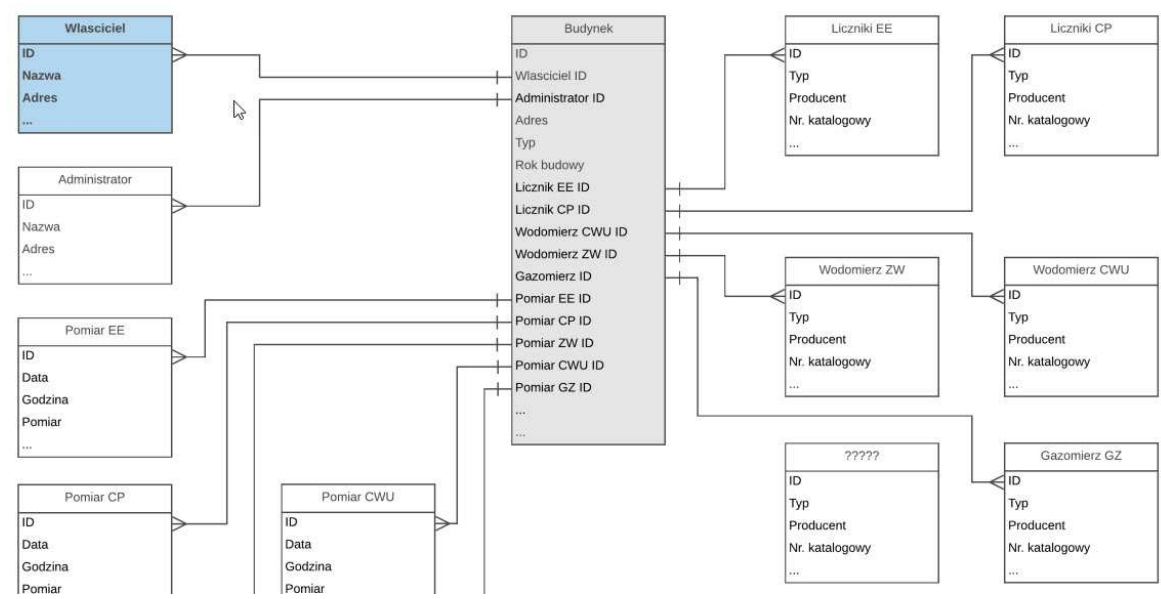

Fig. 2. A fragment of the designed structure of a relational operation database.

Ensuring the reliability of data access and security of storage, both in terms of protection against data loss as well as unauthorised access [14,18,21] constituted an extremely important aspect of the designed structure of the database and the accompanying system software.

Software designed to analyse the collected measurement data is a key element of the database and analytical part of the exploitation data collection and analysis system. The basic objective of the software is to analyse and visualise the collected measurement data as well as automatic generation of recommendations in terms of energy (heat, electricity) and utilities (hot water, cold water, gas, special media, e.g. steam, special gases, etc.) management for individual buildings and clusters of buildings owned/managed by one owner/administrator. The use of the results of operational data analyses will facilitate a significant reduction in the amount of consumed energy and utilities by means of the detection of emergency situations (e.g. water leaks, irrational use of artificial lighting, etc.), among others. Raising the awareness of residents, users and owners who, by obtaining and analysing on-line information on current and archival levels of energy and media consumption, may take measures to limit the irrational use of electricity, heat, gas, hot and cold tap water, is also an extremely important, positive aspect of the implementation of analytical software. A good example of such a scenario may be, for example, the optimisation of daily work schedules for technical services (e.g. cleaners), which can be correlated with daily lighting rhythm and building utilisation characteristics based on the analysis of electricity consumption graphs based on actual operating data obtained from the system registration, archiving and analysis of operating data. In addition, these analyses can serve as a basis for the rational management of buildings by their owners, by optimising modernisation schedules and scopes, e.g. in terms of thermal insulation or reconstruction of heat and electricity sources [33]. Exploitation data collected under such systems can also facilitate environmental and technical decisions regarding the size (power) and the location of new, ecological electricity and heat sources for a given area (housing estate, city, and community).

\section{Conclusions}

The development and implementation of an innovative, distributed registration, archiving and analysis system for exploitation energy/utilities consumption data in buildings of any purpose will promote a significant reduction in electricity, heat and utilities consumption on 
the scale of an entire area in question. The widespread implementation of such a system in an urban area will cover all public facilities and as such, will significantly improve the state of air quality in a given area, will affect the reduction of SMOG, as well as will facilitate rational decision-making regarding the schedules, scales and technical aspects of modernisation of building resources (e.g. thermal insulation). The possibility of using measurement data in documents are important from the point of view of the energy policy pursued in the region, e.g. "Low Emission Economy Programs", "Low Emission Reduction Programs" or "Air Protection Programs" will also be an extremely beneficial aspect of the implementation of the system. Another important feature of the implementation of the project will be the opportunity to familiarise the public with the benefits of optimising the energy management of urban units, which in the long-term will result in an improved awareness in residents and increased potential for the implementation of such projects. The visualisation of exploitation regarding energy/utilities consumption will be an extremely valuable tool for rationalisation of energy systems, for designing energy-efficient buildings, for the selection of heat sources for buildings or building compounds, thus, ensuring their optimal, energy-efficient operation and at the same time, increasing the proportion of renewable energy sources in the energy balance of the region.

\section{References}

1. F. Almeida, M.D. Assuncao, J. Barbosa, V. Blanco, I. Brandic, G. Da Costa, M.F. Dolz, A.C. Elster, M. Jarus, H.D. Karatza, L. Lefnvre, I. Mavridis, A. Oleksiak, A.C. Orgerie, J.M. Pierson, Sustain Comput-Infor 17, 27-42, (2018).

2. T.A. Barbasova, O.V. Kolesnikova, A.A. Filimonova, Enrgy Proced 83, 69-78, (2015).

3. D. Bonilla, M.G. Samaniego, R. Ramos, H. Campbell, Sustain Cities Soc 39, 155-162, (2018).

4. D. Bonino, L. De Russis, Energ Buildings 91, 1-9, (2015).

5. C.F. Calvillo, A. Sanchez-Miralles, J. Villar, Renew Sust Energ Rev 55, 273-287, (2016).

6. A. Capozzoli, M.S. Piscitelli, S. Brandi, Energy Procedia 134, 865-874, (2017).

7. H. Carstens, X. Xia, S. Yadavalli, Renew Sust Energ Rev 82, 2791-2805, (2018).

8. Y. Chen, D. Han, Automat Constr 89, 307-316, (2018).

9. M. Deakin, A. Reid, J Clean Prod 173, 39-48, (2018).

10. V. Fernandez-Anez, J.M. Fernandez-Guell, R. Giffinger, Smart City implementation and discourses: An integrated conceptual model. The case of Vienna, Cities, (2017).

11. M.A. Ferrag, L.A. Maglaras, H. Janicke, Jiang J., Shu, L., Sustain Cities Soc 38, 806$835,(2018)$.

12. C. Foulds, R.A.V. Robison, R. Macrorie, Energ Policy 104, 194-202, (2017).

13. IEA, World Energy Outlook 2012, IEA, 2012

14. A. Jindal, N. Kumar, M. Singh, Future Gener Comp Sy, 2018.

15. Y. Keho, Energ Policy 91, 233-246, (2016)

16. A. Kylili, P.A. Fokaides, Sustain Cities Soc 15, 86-95, (2015).

17. H.X. Li, M. Gul, H. Yu, H. Awad, M. Al-Hussein, Energ Buildings 126, 353-364, (2016).

18. L. Linder, D. Vionnet, J.P. Bacher, J. Hennebert, Enrgy Proced 122, 589-594, (2017).

19. J. Malko, Energia dla wszystkich. Globalne wyzwanie dla sektora energii, Polityka Energetyczna 18, 1, 5-13, (2015)

20. F. Mosannenzadeh, A. Bisello, R. Vaccaro, V. D'Alonzo, G.W. Hunter, D. Vettorato, Smart energy city development: A story told by urban planners, Cities 64, 54-65, (2017).

21. A.A. Munshi, Y.A.R.I. Mohamed, Electr Pow Syst Res 151, 369-380, (2017). 
22. L. Perez-Lombard, J. Ortiz, C. Pout, Energ Buildings 40, 3, 394-398, (2008)

23. B. Regulski, P. Ziembicki, J. Bernasiński, A. Węglarz, Rynek ciepłowniczy w Polsce, Rynek Energii 113, 4, (2014)

24. B.N. Silva, M. Khan, K. Han, Sustain Cities Soc 38, 697-713, (2018).

25. K. Solangi, M. Islam, R. Saidur, N. Rahim, H. Fayaz, Renew Sust Energ Rev 15, 4, 2149-2163, (2011)

26. R.P. Van Leeuwen, J.B. de Wit, G.J.M. Smit, Energ Convers Manag 150, 941-948, (2017).

27. N. Vetterli, M. Sulzer, U.P. Menti, Enrgy Proced 122, 62-67, (2017).

28. A. Węglarz, P. Narowski, The optimal thermal design of residential buildings using energy simulation and fuzzy sets theory, Proceedings of Building Simulation 2011: 12th Conference of International Building, Performance Simulation Association, 585592, (2011).

29. C. Wolfram, O. Shelef, P. Gertler, J Econ Perspect 26, 1, 119-137, (2012)

30. C.T. Yang, S.T. Chen, W. Den, Y.T. Wang, Kristiani E., Future Gener Comp Sy, 2018.

31. L. Zhao, J. Zhang, R.B. Liang, Energ Buildings 66, 41-48, (2013).

32. P. Ziembicki (red.), Rozproszone kogeneracyjne źródła energii dla budynków, University of Zielona Góra, (2013)

33. P. Ziembicki, J. Kozioł, B. Mendecka, Innowacyjne metody zarzadzania w energetyce komunalnej, University of Zielona Góra, (2018)

34. M. Zuccala, E.S. Verga, Enabling Energy Smart Cities through Urban Sharing Ecosystems, Enrgy Proced 111, 826-835, (2017). 